\title{
EN BLOC ESOPHAGECTOMY IMPROVES SURVIVAL FOR STAGE III ESOPHAGEAL CANCER
}

Nasser K. Altorki, MD

Leonard Girardi, MD

David B. Skinner, MD
Objective: The role of en bloc esophagectomy in the surgical treatment of patients with locally advanced esophageal cancer is not well defined. This report attempts to elucidate its impact on survival, in comparison with less extensive resection, among patients with stage III disease. Methods: A prospectively established database was retrospectively analyzed. Results: One hundred twenty-eight patients underwent esophagectomy for carcinoma of the thoracic esophagus between 1988 and 1996 (78 underwent en bloc resection and 50 underwent standard resection). The $\mathbf{3 0}$-day and hospital mortality rates were $3.9 \%$ and $5.4 \%$, respectively, comparable for the two procedures. Fifty-four patients had stage III disease. Overall 4-year survival was $34.5 \%$ after en bloc resection, with a median survival of 27 months $(n=33)$, and $11 \%$ after standard resection $(n=21)$, with a median survival of 12 months $(p=0.007)$. Among patients with stage III disease undergoing a complete resection, 4-year survivals were $36.7 \%$ and $0 \%$ after en bloc and standard resections, respectively $(p=0.001)$. Eighty-six of 128 patients had nodal metastasis. Three-year survivals for patients with N1 disease were $33.9 \%$ and $13 \%$ after en bloc and standard resections, respectively $(p=0.02)$. Conclusion: Among patients with stage III esophageal cancer, en bloc resection appears to significantly improve survival compared with lesser resections. This improvement in survival may be attributable to resection of nodal disease. (J Thorac Cardiovasc Surg 1997; 114:948-56)
$A^{\mathrm{s}}$ s the century draws to an end, the prospects of prolonged survival for patients with esophageal carcinoma remain as dismal as they were nearly 40 years ago. The poor prognosis of this disease persists, despite the significant refinements in operative techniques, refinements in perioperative care, and the introduction of various neoadjuvant modalities. ${ }^{1-3}$ The dramatic and continuing increase in the incidence of adenocarcinoma of the esophagus and cardia lends urgency to the development of im-

From the Department of Cardiothoracic Surgery, The New York Hospital-Cornell Medical Center, New York, N.Y.

Read at the Seventy-seventh Annual Meeting of The American Association for Thoracic Surgery, Washington, D.C., May 4-7, 1997.

Received for publication May 6, 1997; revisions requested June 16, 1997; revisions received August 18, 1997; accepted for publication August 19, 1997.

Address for reprints: Nasser K. Altorki, MD, Director, Division of Thoracic Surgery, Department of Cardiothoracic Surgery, The New York Hospital-Cornell Medical Center, 525 East 68th St., New York, NY 10021.

Copyright (C) 1997 by Mosby-Year Book, Inc.

$0022-5223 / 97 \$ 5.00+0 \quad \mathbf{1 2 / 6 / 8 5 5 2 4}$ proved therapeutic strategies for this disease. ${ }^{4,5}$ The past decade has witnessed an ongoing worldwide debate among surgeons regarding the need for and the efficacy of radical esophageal resections, with most favoring more limited transthoracic or transhiatal resections. ${ }^{6-8}$ Advocates of these latter approaches argue that esophageal carcinoma, once diagnosed, is a systemic disease, and palliation rather than cure should therefore dictate the operative strategy. ${ }^{6} \mathrm{~A}$ few surgical groups, ourselves included, have advocated a more radical resection in the hope of altering the natural history of the disease in patients with limited nodal metastasis. ${ }^{9-11}$ In fact, since 1986 we have favored en bloc esophagectomy for patients with stage I or II esophageal carcinoma, resorting to a more limited resection when preoperative or intraoperative staging suggests more advanced disease. ${ }^{12}$ This approach was rooted in our belief that the more extensive en bloc resection might not be justified given the unlikely possibility of improving survival among patients with stage III disease. Interestingly, however, an interim analysis of our results in 1992 suggested that the morbidity and mortality for radical and less exten- 
sive resections were, at least in our experience, similar. We therefore altered our surgical strategy as of June 1992, and we have since performed en bloc resection in patients with all stages of esophageal carcinoma, with the obvious exceptions of those with visceral metastasis or T4 lesions. This report analyzes the outcome of this strategy in this group of patients.

\section{Methods}

Between January 1988 and September 1996, 128 patients with carcinoma of the thoracic esophagus underwent surgical resection at The New York Hospital-Cornell Medical Center. All patients underwent a preoperative diagnostic and staging evaluation that included an esophagogastroduodenoscopy, a computed tomographic scan of the chest and upper abdomen, and bronchoscopy in patients with tumors of the upper and middle thirds. Endoscopic ultrasonography was used in a significant number of cases; however, its utility in clinical decision making was restricted to determining which patients had T4 lesions and were not considered operative candidates. Patients were evaluated for their overall performance status according to standard Eastern Cooperative Oncology Group (ECOG) criteria (Table I). Additionally, all patients underwent evaluation of pulmonary and cardiac function to determine their ability to withstand the planned procedure. Generally, patients with a forced expiratory volume in 1 second of less than 1.5 L despite aggressive physiotherapy and bronchodilator therapy were considered ineligible for resection, but decisions were made individually, depending on the stage of the disease and the presence of other comorbid factors. Any cardiac disease was carefully evaluated, up to and including coronary angiography in selected cases. Preoperative cisplatinbased chemotherapy was used in nine patients, five of whom underwent an en bloc resection and four of whom underwent a standard resection.

Surgical procedures. Before June 1992, patients were selected to receive an en bloc resection if preoperative or intraoperative staging predicted stage I or II disease. If staging maneuvers suggested transmural disease with obvious nodal metastasis or celiac nodal disease, or if visceral metastasis was unexpectedly encountered, then a standard resection was performed. Since June 1992, all patients have undergone en bloc resection unless intraoperative exploration revealed unexpected visceral metastasis, in which case a standard resection was done.

For tumors of the gastroesophageal junction and the lower and middle thirds of the esophagus, an en bloc resection was accomplished by excision of the tumor within a wide envelope of surrounding tissue including both pleural surfaces laterally, the pericardium anteriorly, and the thoracic duct posteriorly. For tumors that traversed the hiatus, the envelope of tissue included a 1 -inch circumferential cuff of diaphragm as well. The ensuing lymph node dissection included all lymphatic and areolar tissue between the tracheal bifurcation and the celiac axis, including the retroperitoneal, common hepatic, and
Table I. ECOG performance scale

\begin{tabular}{cl}
\hline Grade & \multicolumn{1}{c}{ Description } \\
\hline 0 & Normal activity \\
1 & $\begin{array}{c}\text { Showing symptoms of disease, but ambulatory and } \\
\text { able to carry out activities of daily living }\end{array}$ \\
2 & Out of bed more than $50 \%$ of time; occasionally \\
& needs assistance \\
3 & In bed more than $50 \%$ of time; needs nursing care \\
4 & Bedridden; may need hospitalization \\
\hline
\end{tabular}

splenic nodal tissue. Upper-third tumors were resected within the constraints imposed by the narrow confines of the superior mediastinum; however, excision of the thoracic duct and the previously described lymphadenectomy were performed in every case. In 32 patients, the lymphadenectomy was extended to include the nodes along both recurrent nerves as well as the deep cervical lymph nodes (three-field lymphadenectomy). When less extensive resections were performed, the tumor-bearing esophagus was resected along with the periesophageal, parahiatal, and left gastric nodal chains. No attempt was made to resect the thoracic duct or perform a retroperitoneal dissection of the upper abdomen. Regardless of the type of resection, the gastrointestinal tract was divided with 8 to $10 \mathrm{~cm}$ proximal and distal margins.

Resections were considered curative when no gross residual disease was left behind at the conclusion of the procedure or found by frozen-section examination of the surgical margins of resection $\left(\mathrm{R}_{0}\right)$. Resections were considered palliative if microscopic disease $\left(R_{1}\right)$ or residual gross tumor $\left(R_{2}\right)$ were present either at the margins of resection or within the mediastinum or upper abdomen. The use of the $R$ descriptors decreases the element of subjectivity in determining the curative or palliative nature of a given procedure.

Reconstruction. Alimentary tract continuity was restored with a greater curvature gastric tube in 112 patients and a colon interposition in 15 . Reconstruction was delayed in one patient who underwent a cervical esophagostomy and gastrostomy. Forty anastomoses were located in the mediastinum and 87 were located in the neck.

Follow-up. Most patients were seen at 3-month intervals during the first 2 years, every 6 months for the next year, and yearly thereafter. Patients referred from distant geographic locations were followed up by their local physicians. Follow-up was obtained in such instances either by direct physician contact or patient contact.

Statistical analysis. Survival time was measured as the time from the procedure until death (including operative death) or until last (most recent) follow-up. Survival distribution was estimated by the product-limit method and compared by the log-rank test. The confidence interval (CI) around the probability of survival is symmetric and was calculated by taking twice the standard error and adding or subtracting from the point estimate to obtain the upper and lower bounds of the interval. The CI around median survival time is not necessarily symmetric (a well-known property of CIs around medians). The upper limit of the CI may not be calculable for certain patterns of data (e.g., when the number of "events" after 
Table II. Mortality and morbidity

\begin{tabular}{|c|c|c|c|}
\hline & $\begin{array}{l}\text { Standard } \\
\text { resection } \\
(n=50)\end{array}$ & $\begin{array}{l}\text { En bloc } \\
\text { resection } \\
(n=78)\end{array}$ & $\begin{array}{c}\text { Total } \\
(n=128)\end{array}$ \\
\hline In-hospital death & $3(6 \%)$ & $4(5.1 \%)$ & \\
\hline \multicolumn{4}{|l|}{ Complications } \\
\hline Respiratory & $13(26 \%)$ & $19(24 \%)$ & $32(25 \%)$ \\
\hline Pneumonia & 2 & 4 & \\
\hline Prolonged intubation & 10 & 13 & \\
\hline Tracheostomy & 2 & 5 & \\
\hline Atelectasis* & 2 & 6 & \\
\hline Cardiac & $4(8 \%)$ & $3(3.8 \%)$ & $7(5.4 \%)$ \\
\hline Myocardial infarction & 1 & - & \\
\hline Arrhythmia & 2 & 2 & \\
\hline Pericarditis & 1 & 1 & \\
\hline Leaks & $8(16 \%)$ & $10(12.8 \%)$ & $18(14 \%)$ \\
\hline Recurrent nerve injury & $1(2 \%)$ & $3(3.8 \%)$ & $4(3 \%) \ddagger$ \\
\hline Chylothorax & 2 & - & $2(1.5 \%)$ \\
\hline Infection & 4 & 6 & 10 \\
\hline Bleeding & - & 2 & 2 \\
\hline \multicolumn{4}{|l|}{ Other } \\
\hline Pancreatitis & 1 & 一 & \\
\hline Bowel obstruction & 1 & - & \\
\hline Delirium tremens & - & 3 & \\
\hline
\end{tabular}

*Requiring bronchoscopy.

$\dagger$ Hemodynamically significant.

$\Varangle$ Two permanent, two transient.

Table III. Staging, $p T M N$

\begin{tabular}{lrrr}
\hline & Total & $\begin{array}{c}\text { En bloc } \\
(n=78)\end{array}$ & $\begin{array}{c}\text { Standard } \\
(n=50)\end{array}$ \\
\hline T/N status & & & \\
Tis & 4 & 4 & 0 \\
T1 & 16 & 15 & 1 \\
T2 & 22 & 15 & 7 \\
T3 & 77 & 41 & 36 \\
T4 & 9 & 3 & 6 \\
N0 & 42 & 31 & 11 \\
N1 & 86 & 47 & 39 \\
$p$ TNM & & & \\
Stage 0 & 4 & 4 & - \\
Stage I & 14 & 13 & 1 \\
Stage IIA & 20 & 13 & 7 \\
Stage IIB & 13 & 9 & 4 \\
Stage III & 54 & 33 & 21 \\
Stage IV & 23 & 6 & 17 \\
M1 (lymph) & & 5 & 12 \\
M1 (organ) & & 1 & 5 \\
\hline
\end{tabular}

the median survival estimate is disproportionately small in comparison to the number of censored observations). ${ }^{13,14}$ Comparisons between the standard and en bloc procedures for patients with stage III disease were done by the two-sample $t$ test for ordinal variables (e.g., age, tumor size) and by Fisher's Exact Test (or $\chi^{2}$ test where appropriate) for categoric variables (e.g., sex, cell type). All tests were performed at a 0.05 significance level, with no adjustments for multiple testing.

\section{Results}

One hundred twenty-eight patients underwent esophagectomy for carcinoma of the thoracic esophagus. There were 101 male and 27 female patients, with a median age of 62 (range 38 to 87 ) years. All patients had an ECOG performance status of 0 to 2 . Tumors were located in the lower third of the thoracic esophagus (below the level of the inferior pulmonary vein) in 86 patients and precisely at the gastroesophageal junction in 16 patients. Twentyone patients had middle-third tumors, whereas in five the tumors were located above the tracheal bifurcation. En bloc esophagectomy was performed in 78 patients, 32 of whom also underwent a threefield lymph node dissection. Fifty patients underwent a less extensive resection, primarily by a transthoracic route. Resections were considered curative $\left(R_{0}\right)$ in 113 cases (37 standard, 76 en bloc). Resections were palliative in 15 cases ( 2 en bloc, 13 standard) because of the presence of residual tumor 
Table IV. Survival by stage for en bloc versus standard resection

\begin{tabular}{|c|c|c|c|c|c|c|c|}
\hline & \multicolumn{3}{|c|}{ Standard resection } & \multicolumn{3}{|c|}{ En bloc resection } & \multirow[b]{2}{*}{ p Value } \\
\hline & $n$ & 4 yr surv $(\%)$ & $\begin{array}{l}\text { Median surv } \\
(\text { mo })\end{array}$ & $n$ & 4 yr surv $(\%)$ & Median surv (mo) & \\
\hline Stage I & 1 & $\div$ & - & 13 & 71.9 & - & - \\
\hline Stage II & 11 & 13 & $20(15-29)$ & 22 & 32.9 & $38(23-?)^{*}$ & 0.02 \\
\hline \multicolumn{8}{|l|}{ Stage III } \\
\hline All resections & 21 & $11(0-25)$ & $12.6(8-14)$ & 33 & $34.5(12-56)$ & $27(17-?)^{*}$ & 0.007 \\
\hline $\mathrm{R}_{0}$ resections & 16 & $0(0-22)$ & $12(8-14)$ & 31 & $36.7(12-60)$ & $27.3(17-?)^{*}$ & 0.001 \\
\hline
\end{tabular}

The $95 \%$ CIs are given in parentheses. surv, Survival.

*Upper limit of Cl could not be computed.

$\left(\mathrm{R}_{1}\right.$ or $\left.\mathrm{R}_{2}\right)$ at the conclusion of the procedure. Resection was considered incomplete because of the presence of distant visceral metastasis in six cases, unresectable nodal disease in seven, and positive esophageal margins in two.

In-hospital mortality rate. The overall in-hospital mortality rate was $5.4 \%$, with seven in-hospital deaths (30-day mortality rate of $3.9 \%$ ). There were four deaths in the en bloc group $(5.1 \%)$ and three in the limited-resection group $(6 \%)$.

Operative morbidity. Seventy three patients (57\%) had uncomplicated postoperative courses. Complications occurred in 55 patients, for an operative morbidity of $43 \%$. Respiratory complications and anastomotic leaks were the most common morbidities for both procedures (Table II).

Pathology and postsurgical staging. There were 38 squamous cell carcinomas and 90 adenocarcinomas. Tumors were considered well differentiated in 18 cases, moderately differentiated in 43 , and poorly differentiated in 67. Staging was based on the TNM staging system of the American Joint Committee on Cancer (Table III). Overall, there were four patients with stage 0 disease, 14 with stage $I, 20$ with stage IIA, 13 with stage IIB, and 54 with stage III. Twenty-three patients had stage IV disease; six had distant visceral metastases and 17 were found to have stage IV disease on the basis of cancer metastasis to the celiac or cervical nodes. Overall, 86 patients $(68 \%)$ had node-positive disease.

Actuarial survival. Follow-up was complete for $100 \%$ of patients until death or April 1997. Overall survival was $25 \%$ for all 128 patients, including operative deaths. Four-year survival for the 50 patients undergoing limited resection was $8 \%$ ( $95 \%$ CI $0 \%$ to $18 \%$ ), compared with $41.5 \%$ (95\% CI $25-57 \%$ ) for the en bloc group. For patients with curative resections $\left(\mathrm{R}_{0}\right)$, 4-year survival and median survival after en bloc resections were $42.5 \%$ (95\% CI $26 \%$ to $58 \%$ ) and 38 months, respectively, versus $11.4 \%$ (95\% CI $0 \%$ to $20 \%)$ and 13.8 months after standard resections $(p=$ 0.0002 , log-rank). Although these differences were statistically significant, they were at least partly caused by the selection of all patients with stage 0 and stage I disease to receive en bloc resection and resorting to standard resections for most patients with stage IV disease.

Thirteen patients with stage I disease and four patients with stage 0 (TisN0) underwent en bloc resection. Their survivals at 4 years were $75 \%$ and $100 \%$, respectively. Only one patient with stage I disease underwent a standard resection. Patients with stage IIA and IIB disease were grouped together for survival analysis because of their relatively small numbers. Survival of patients with stage II disease is shown in Table IV and seems to favor the en bloc group ( $p=0.02, \log$-rank).

Fifty-four patients had stage III disease; 33 of these underwent en bloc esophagectomy and 21 underwent a limited resection. Four-year survival and median survival for the limited-resection group were $11 \%$ and 12 months, respectively. After en bloc resection, the 4-year survival rate was $34.5 \%$, with a median of 27 months (Table IV, Fig. 1). This improvement in survival by en bloc resection for patients with stage III disease was statistically significant when compared with survival after standard resection ( $p=0.007, \log$-rank). Thirty-one patients had a curative en bloc resection, with a 4-year survival rate of $36.7 \%$ (median 27 months). Sixteen patients had a curative standard resection, with no 4-year survivors (median 12 months) ( $p=0.001$, log-rank; Fig. 2). 


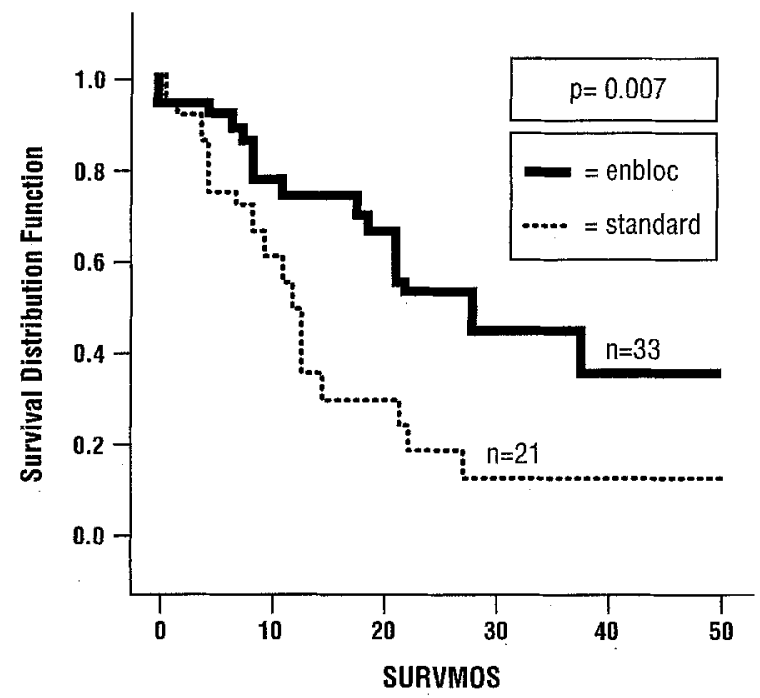

Fig. 1. Actuarial survivals for patients undergoing resection of stage III disease. SURVMOS, Survival in months.

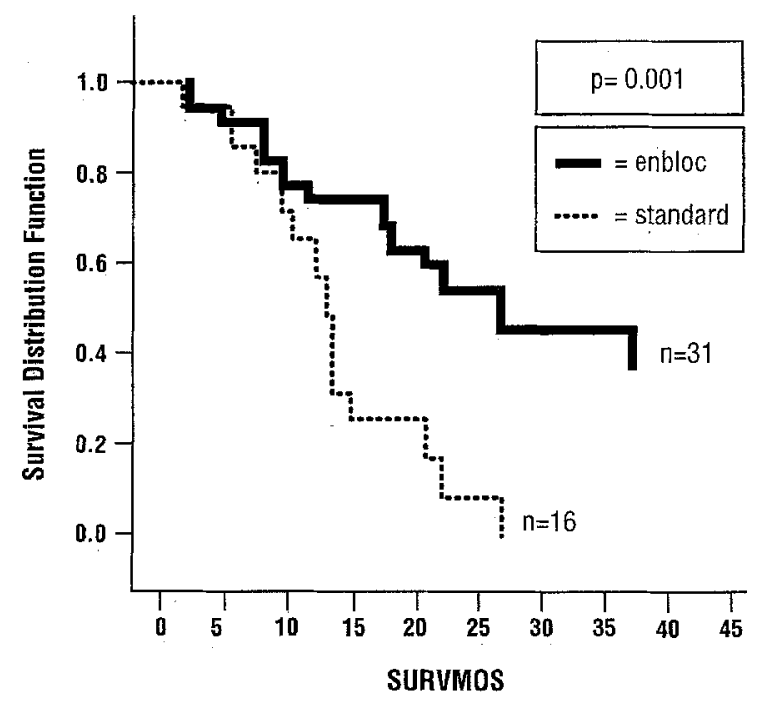

Fig. 2. Actuarial survivals for patients with curative resection of stage III disease. SURVMOS, Survival in months.

Because most retrospective analyses of this type carry an inherent selection bias, we compared both groups for several criteria that might have unduly favored the en bloc resection group (Table V). There were no statistically significant differences between the groups in age, sex, tumor cell type or differentiation, and patient performance status. Although patients in the limited-resection group tended to have larger tumors $(4.5 \mathrm{vs} 3.7 \mathrm{~cm})$ and

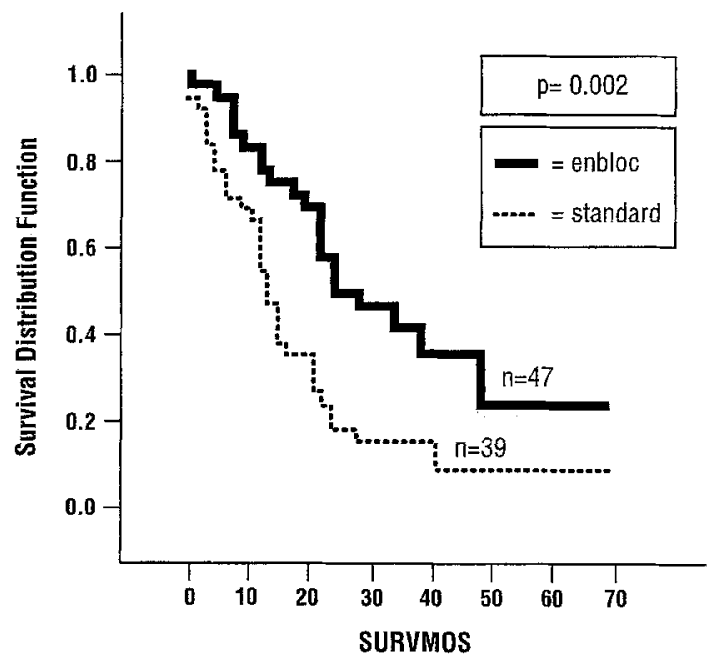

Fig. 3. Actuarial survivals for 86 patients undergoing resection with positive nodes. SURVMOS, Survival in months.

patients in the en bloc group tended to have more positive nodes per patient ( 4.1 vs 3.5 ), these differences did not attain statistical significance.

Forty-two patients had node-negative disease. Thirty-one underwent en bloc resection and 11 underwent limited resection. Survival rates for patients with node-negative disease are shown in Table VI. The mean number of resected nodes in the patients with node-negative disease was 35.9 nodes/ patient for en bloc resection and 19.5 nodes/patient for limited resection $(p=0.03)$. Eighty-six patients had metastatic carcinoma in their lymph nodes. Three-year survival for 47 patients who underwent en bloc resection was $33.9 \%$ (median 23 months). For patients with node-positive disease who underwent limited resection $(n=39)$, the corresponding survival figure was $13 \%$ (median 12.6 months; Fig. 3, Table VI). These differences in survival were statistically significant, with a $p$ value of 0.002 by the $\log$-rank test. The mean number of positive nodes per patient was slightly higher for the limitedresection group (5 positive nodes/patient) compared with the en bloc group (4.1 positive nodes/patient); however, the difference was not statistically significant $(p=0.22)$.

\section{Discussion}

The results of this study seem to support our current recommendation that en bloc esophagectomy be offered to patients with stage I, II, and III esophageal cancer who are considered candi- 
Volume 114, Number 6

Table V. Analysis of variance for patients with stage III disease: Enbloc versus standard resection

\begin{tabular}{lcccl} 
& Standard $(n=21)$ & Enbloc $(n=33)$ & $p$ Value & \multicolumn{1}{c}{ Test } \\
\hline Age (yr) & $63.8 \pm 13^{*}$ & $58.5 \pm 8.91^{*}$ & 0.07 & $t$ test \\
Sex & 17 male, 4 female & 29 males, 4 females & 0.69 & Fisher's Exact Test \\
Cell type & 12 adenocarcinoma, 9 squamous & 24 adenocarcinoma, 9 squamous & 0.17 & $\chi^{2}$ \\
& cell carcinoma & cell carcinoma & & \\
Differentiation & 1 well, 6 moderate, 14 poor & 2 well, 7 moderate, 24 poor & 0.885 & Fisher's Exact Test \\
ECOG status & 20 status 1, 1 status 2 & 1 status 0,32 status 1 & 0.63 & Fisher's Exact Test \\
Tumor size (cm) & $4.5 \pm 2.15^{*}$ & $3.7 \pm 1.71^{*}$ & 0.1 & Student $t$ test \\
Positive nodes/patient & $3.5 \pm 3.26^{*}$ & $4.1 \pm 2.82^{*}$ & 0.4 & Student $t$ test \\
\hline
\end{tabular}

Table VI. Survival by nodal status for en bloc versus standard resection

\begin{tabular}{|c|c|c|c|c|c|c|c|}
\hline \multirow[b]{2}{*}{$N$ status } & \multicolumn{3}{|c|}{ Standard resection } & \multicolumn{3}{|c|}{ En bloc resection } & \multirow[b]{2}{*}{$p$ Value } \\
\hline & $n$ & 3 yr surv $(\%)$ & Median surv (mo) & $n$ & 3 yr surv (\%) & Median surv (mo) & \\
\hline No & 11 & $27(0-59)$ & $28(8.6-50.0)$ & 31 & $68(46-90)$ & NR $(38-?)^{*}$ & 0.01 \\
\hline N1 & 39 & $13(1-25)$ & $12(10.0-15.0)$ & 47 & $33.9(14-53)$ & $23(20-47)$ & 0.002 \\
\hline
\end{tabular}

The $95 \%$ CIs are given in parentheses. surv, Survival; $N R$, not reached.

*Upper limit of CI could not be computed.

dates for curative $\left(\mathrm{R}_{0}\right)$ surgical resection. In our view, this strategy is supported by four basic arguments.

First, the more extensive lymphadenectomy offered by the en bloc technique allows better staging, as evidenced by the improved survival among patients with node-negative disease treated by en bloc resection compared with similar patients undergoing a more standard resection. Undoubtedly, a significant number of the latter group had their disease understaged; their inferior survival cannot be explained otherwise. The understaging of disease in patients receiving less extensive procedures has been shown previously by other investigators. ${ }^{15,16}$ Akiyama and colleagues ${ }^{16}$ reported that the survival of patients without nodal metastasis was $83.9 \%$ after three-field dissection compared with $55 \%$ for patients treated by a two-field lymphadenectomy. We recently reported our own preliminary experience with three-field lymphadenectomy for squamous cell carcinoma and adenocarcinoma of the esophagus. ${ }^{17}$ The prevalence of nodal metastasis in that series of patients was $73 \%$, compared with $68 \%$ in this report. Significantly, however, $20 \%$ of patients with negative nodes in the mediastinum and abdomen had nodal metastasis in the cervical or recurrent laryngeal nodes. These data, as well as those of such others as Akiyama and colleagues, ${ }^{16}$ strongly imply that understaging is directly related to the extent of the lymphadenectomy performed.

Second, although the presence of nodal metastasis undoubtedly results in diminished survival, pro- longed survival and even cure may occasionally be possible after extended lymphadenectomy. Lieberman and associates ${ }^{18}$ reported a 3-year survival of $37 \%$ among 87 patients in whom nodal metastasis was limited to one to three nodes. Additionally, Akiyama and colleagues ${ }^{16}$ reported a $28 \%$ 5-year survival among patients with positive nodes after esophagectomy with radical mediastinal and abdominal lymphadenectomy. Impressively, several Japanese surgeons have recently reported 5-year survival rates in the $20 \%$ range after three-field dissection for patients in whom metastatic carcinoma extended to the cervical nodes. ${ }^{15,16,19}$ Although these latter results have yet to be reproduced outside Japan, they suggest that at least in a subset of patients, the disease remains localized and therefore potentially curable. In this report, the survival of patients with $\mathrm{N} 1$ disease treated by en bloc resection was $34 \%$ at 3 years, compared with only $13 \%$ for those treated by more limited resections. The groups appear reasonably similar, because the mean number of positive nodes per patient was not significantly different for the two procedures. It thus appears that, contrary to commonly held belief, resection of nodal metastasis may favorably affect survival and may even be curative for some patients. One caveat, however, is the relatively short follow-up period in this report, because we have begun to encounter recurrences as late as 30 to 36 months after resection. It is concievable that a more radical resection simply shifts the survival curve toward the right, without having a major impact on "cure" rates. 
Third, and perhaps most significantly, the results after en bloc resection in patients with stage III disease reported here may increase the chances of prolonged survival in the substantial number of patients initially seen with this disease stage. Survival at 4 years was $34 \%$ after en bloc resection compared with $11 \%$ after limited resection. The improvement in survival after en bloc resection was evident, even when only patients with curative resections were considered. Within the constraints of this retrospective analysis, we could not detect any nonexperimental factor that might have imparted a survival advantage to the en bloc group. Both groups had similar demographic features, pathologic characteristics, and performance statuses. The tendencies toward larger tumors in the standard resection group and toward more positive nodes per patient in the en bloc group did not prove to be of statistical significance. Additionally the $11 \%$ 4-year survival after limited resection in this report is basically within the range of survival rates reported by others for stage III esophageal cancer. Lieberman and associates $^{18}$ reported a 5 -year survival of approximately $17 \%$ among 136 patients with stage III disease treated primarily by transthoracic esophagectomy. Killinger and coworkers ${ }^{20}$ reported a $10 \%$ 5-year survival for 132 patients with stage III disease, whereas Orringer, Marshall, and Stirling ${ }^{21}$ reported a 5 -year survival rate of $12 \%$ for patients with similarly staged disease treated by transhiatal esophagectomy. On the other hand, the 34\% 4-year survival reported here for patients with stage III disease after en bloc resection appears similar to that reported by others who routinely employ equally radical techniques. Five-year survival for stage III esophageal cancer after esophagectomy with two-field lymphadenectomy was reported by Akiyama and colleagues ${ }^{16}$ to be $38.5 \%$ and by Kato and associates ${ }^{22}$ to be $27 \%$.

Fourth, most randomized trials with either preoperative chemotherapy or chemoradiotherapy have failed to show a survival advantage beyond that achieved by surgical intervention alone. ${ }^{23-26} \mathrm{~A}$ recently reported randomized trial for patients with adenocarcinoma compared preoperative fluorouracil, cisplatin, and radiation of $40 \mathrm{~Gy}$ followed by resection with resection alone. ${ }^{27}$ The 5-year survival in the combined-modality group was $32 \%$, compared with $6 \%$ in the resection-alone arm. Although this was a statistically significant difference, the pretreatment staging of both groups was limited. More significantly, the historical 5-year survival for surgical resection at that institution was $23 \%$, a striking difference when compared with the results of the surgical arm of the study. ${ }^{27}$ A recently concluded national multicenter study randomly assigned patients to preoperative chemotherapy (fluorouracil and cisplatin) versus resection alone. ${ }^{28}$ The preliminary results suggest no significant difference between the two arms of the study. Clearly, the bulk of current evidence suggests that preoperative therapy combined with a standard resection has thus far produced no significant improvement in survival rates. These disappointing results have led some medical and radiation oncologists to question the relevance of surgical intervention in this disease, particularly since a 30\% 5-year survival rate has been reported after chemoradiotherapy alone. ${ }^{29}$ There appears to be a dire need to reassess the current surgical strategies if one is to expect a change in this grim outlook. We believe that the salutary effect of radical resections, particularly with respect to nodepositive disease and decreased local recurrence rates, may be a step in the right direction.

Undoubtedly, the controversy regarding how "big" the procedure should be will continue. Some might suggest a randomized trial comparing radical and less radical surgical techniques. A randomized trial, however, can only compare potentially comparable strategies. The unquestionable deficiency of limited resections in providing adequate staging will not vanish in a randomized setting. This report, despite the relatively small number, comes close to what we believe is an adequate and fair assessment of the roles of both surgical techniques in the treatment of esophageal carcinoma.

\section{REFERENCES}

1. Muller JM, Erasmi H, Stelzner M, et al. Surgical therapy of oesophageal carcinoma. Br J Surg 1990;77:845-57.

2. Gignoux M, Roussel A, Paillot B, et al. The value of preoperative radiotherapy in esophageal cancer: results of a study of the EORTC. World J Surg 1987;11:426-32.

3. Naunheim KS, Petruska PJ, Roy TS, et al. Preoperative chemotherapy and radiotherapy for esophageal carcinoma. J Thorac Cardiovasc Surg 1992;5:887-95.

4. Blot WJ, Devesa SS, Kneller RW, et al. Rising incidence of adenocarcinoma of the esophagus and gastric cardia. JAMA 1991;265:1287-9.

5. Blot WJ, Devesa SS, Fraumeni JF Jr. Continuing climb rates of esophageal adenocarcinoma: an update [letter]. JAMA 1993;270:1320.

6. Orringer MB, Sloan H. Esophagectomy without thoracotomy. J Thorac Cardiovasc Surg 1978;76:643-54.

7. Tilanus HW, Hop WC, Langenhorst BL, et al. Esophagectomy with or without thoracotomy: is there any difference? J Thorac Cardiovasc Surg 1993;105:898-903. 
8. Goldminc M, Maddern G, Le Prise E, et al. Oesophagectomy by a transhiatal approach or thoracotomy: a prospective randomized trial. Br J Surg 1993;80:367-70.

9. Skinner DB. Enbloc resection for neoplasms of the esophagus and cardia. J Thorac Cardiovasc Surg 1983;85:59-69.

10. Hagen JA, Peters JH, DeMeester TR. Superiority of extended en bloc esophagectomy for carcinoma of the lower esophagus and cardia. J Thorac Cardiovasc Surg 1993;106: 850-8.

11. Lerut T, De Leyn P, Coosemans W, et al. Surgical strategies in esophageal carcinoma with emphasis on radical lymphadenectomy. Ann Surg 1992;216:583-90.

12. Skinner DB, Little AG, Ferguson MK, Soriano A, et al. Selection of operation for esophageal cancer based on staging. Ann Surg 1986;204:391-441.

13. Zar J. Biostatistical analysis, 2nd ed. Englewood Cliffs (NJ): Prentice Hall, 1984. p. 390.

14. Brookmeyer R, Crowley J. A confidence interval for the median survival time. Biometrics 1982;38:29-42.

15. Isono K, Sato HK, Nakayama K. Results of nationwide study on the three-field lymph node dissection of esophageal cancer. Oncology 1991;48:411-20.

16. Akiyama $H$, Tsurumaru $M$, Udagawa $H$. Radical lymph node dissection for cancer of the thoracic esophagus. Ann Surg 1994;220:364-73.

17. Altorki NK, Skinner DB. Occult cervical nodal metastasis in esophageal cancer: preliminary results of three-field lymphadenectomy. J Thorac Cardiovasc Surg 1997;113: 540-4.

18. Lieberman MD, Schriver CD, Bleckner S, Burt M, et al. Carcinoma of the esophagus: prognostic significance of histologic type. J Thorac Cardiovasc Surg 1994;109:130-9.

19. Kato $H$, Tachimori $Y$, Watanabe $H$, lizuki $T$, Terui $S$, Itabashi $\mathrm{M}$, et al. Lymph node metastasis in the thoracic esophageal carcinoma. J Surg Oncol 1991;48:106-11.

20. Killinger WA, Rice TW, Adelstein TW, Medendorp SV, et al. Stage II esophageal carcinoma: the significance of $\mathrm{T}$ and N. J Thorac Cardiovase Surg 1996;111:935-40.

21. Orringer MB, Marshall B, Stirling MC. Transhiatal esophagectomy for benign and malignant disease. J Thorac Cardiovasc Surg 1993;105:265-77.

22. Kato $\mathrm{H}$, Tachimori $\mathrm{Y}$, Watanabe $\mathrm{H}$, et al. Lymph node metastasis in thoracic esophageal carcinoma. J Surg Oncol 1991;48:106-11.

23. Roth JA, Pass HU, Flanagan MM, et al. Randomized clinical trials of preoperative and postoperative adjuvant chemotherapy with cisplatin, vindesine, and bleomycin for carcinoma of the esophagus. J Thorac Cardiovasc Surg 1988;96:242-8.

24. Schlag P. Randomisierte Studie zur praoperativen chemotherapie beim plattenepithelcarcinom des oesophagus. Chirurg 1992;63:709-11.

25. Kelsen DP, Minsky B, Smith M, et al. Preoperative therapy for esophageal cancer. A randomized comparison of chemotherapy versus radiation therapy. J Clin Oncol 1990;8:135261.

26. Bosset JF, Gignoux M, Triboulet JP, et al. Randomised phase III clinical trial comparing surgery alone versus pre-operative combined radiochemotherapy (XRT-CT) in stage I-II epidermoid cancer of the esophagus. Preliminary analysis: a study of the FFCD (French group) No. 8805 and EORTC No. 40881 [abstract]. Proc Am Soc Clin Oncol 1994;13:197.
27. Waish TN, Noonan N, Hollywood D, Kelly A, et al. A comparison of multimodal therapy and surgery for esophageal adenocarcinoma. N Engl J Med 1996;35:462-7.

28. Kelsen DP, Ginsburg R, Qian C, Gunderson L, et al. Chemotherapy followed by operation versus operation alone in the treatment of patients with localized esophageal cancer: a preliminary report of intergroup study 113 (RTOG 89-11) [abstract]. Meeting of the American Society of Clinical Oncology (ASCO), Denver. 1997.

29. Herskovic A, Martz K, Al-Sarraf M, et al. Combined chemotherapy and radiotherapy compared with radiotherapy alone in patients with cancer of the esophagus. $\mathrm{N}$ Engl $\mathrm{J}$ Med 1992;326:1593-8

\section{Discussion}

Dr. Victor F. Trastek (Rochester, Minn.). Dr. Altorki, I congratulate you on a fine presentation that further updates us on the results of en bloc esophagectomy. The treatment of esophageal carcinoma remains a challenge, and attempts at different forms of treatment, whether aimed at a local or a systemic approach, remain controversial. You pose the following question: Does extending the margins of resection radially and harvesting more lymph nodes improve survival in stage III disease? The data presented are interesting and compelling. The mortality rate of $5.4 \%$ is acceptable, morbidity remains significant, and survival is encouraging. However, without a prospective, randomized format, the question posed remains unanswered. You do call for such a study in your conclusion. When you design this study, I urge you to make comparisons between techniques on the basis of mortality, morbidity, survival at 5 years, quality of life, and costs.

I have several questions: (1) Did the patients receive any other forms of therapy? If so, could this have influenced the results? (2) There were 87 patients who had cervical anastomoses. Was an en bloc approach used in the cervical area? (3) How do you currently manage patients who are found to have bulky lymphadenopathy on computed tomography or who have a positive lymph node found by ultrasonographically guided needle biopsy?

I commend you on acquiring excellent results from an extensive operation and providing some light in what is usually a dark room. I look forward to your results from a prospective, randomized study.

Dr. Mark Krasna (Baltimore, Md.). I too congratulate you and your colleagues on an excellent presentation and excellent results. In a recent article from your group on the results of en bloc resection, you not only noted improved survival but also noted that the lymph node harvest was increased with this technique. I believe that in that recent paper on en bloc resection with three fields, you noted that the incidence of thoracic lymph node metastasis was 10 of 30 cases, actually lower than perhaps thought by Akiyama and others in the last decade, and most of the lymph node metastases were from either the supraclavicular dissection or the abdominal dissection. I wonder if you could point out for this group of patients with stage III disease with en bloc resection what percentage had positive thoracic lymph nodes, versus either abdominal or cervical lymph nodes. 
Dr. Altorki. Thank you for your comments. To answer Dr. Trastek's questions, adjuvant therapy in the form of preoperative chemotherapy was given to nine patients in this study, evenly distributed between the groups. Preoperative radiation was never used. Postoperative radiation was not used for patients with N0 disease, nor was postoperative chemotherapy. Patients with N1 disease received a "cocktail du jour" in terms of chemotherapy through the duration of the study, and almost everybody in both groups got it. To my knowledge, there is no evidence to date that shows a survival advantage from postoperative chemotherapy.

We performed a neck anastomosis in 87 cases, but a neck dissection, as implied by the three fields, was only done in 32 cases. To date, our approach to patients with positive nodes, whether detected by ultrasonography or computed tomography, has primary been surgical resection, in the belief that there are no data, except perhaps for one study, that support the use of preoperative therapy. So our approach has been primary surgical resection. We are going to start an institutional study that involves preoperative chemotherapy followed by en bloc resection.

To answer Dr. Krasna's question, what we have shown in the three-field study is that in patients with negative mediastinal and abdominal nodes, roughly $20 \%$ of patients have positive nodes in the neck. Overall, among all patients, the prevalence of nodal metastasis in the thorax was about $30 \%$. In this study, we did not specifically look at the distribution of nodal metastases, but I suspect it would be the same as that in our three-field dissection. 